\title{
Crossrail project: engineering design management on the Elizabeth line, London
}

Jean-Marc Barsam BSC, CEng, MICE

Project Engineer, Crossrail Ltd; CH2M/Halcrow Group Ltd, London, UK

David Harris BSC, MSC, DIC, CEng, MICE, CGeol, FGS

C121 SCL Tunnels Package Manager, Mott MacDonald Group Ltd,

Croydon, UK
Adrian Hooper BEng, MSc, CEng, MICE, MAPM

Former Engineering Manager, Crossrail Ltd, London, UK

This paper describes the design management for the central tunnelled section of the $f 14 \cdot 8$ billion Crossrail project to deliver the Elizabeth line east-west railway across London. It explains why the processes, procedures and areas of responsibilities of the designers and employer needed to be robust and resilient to cope with the levels of design change experienced at all stages of the project. In particular, it shows how the size and procurement of design packages required careful management of numerous interfaces and the challenges this posed.

\section{Introduction}

The central tunnelled section of the $£ 14.8$ billion Crossrail project to deliver the Elizabeth line east-west railway across London extends from Paddington in the west to Stratford in the east and Abbey Wood in the south-east (Figure 1).

Project undertaker Crossrail's mission is to deliver a worldclass railway that will 'move London forward'. Together with a project-wide commitment to values of safety, inspiration, respect, collaboration and integrity, this helped to unite the diverse and numerous individuals and organisations working on the programme.

This paper describes the design management process for delivering the civil and structural engineering for the central section. It shows how successful delivery of an integrated and sustainable transportation system is dependent on effective coordination, communication and collaboration across project interfaces, as well as technically proficient engineering design.

\section{Background}

The origins of the Crossrail project are described in detail elsewhere (Crossrail, 2016; Fergusson, 2001; Hebbert, 2013; Tucker, 2017). The hybrid bill introduced to the UK parliament in 2005 was the culmination of over 60 years of planning, design studies and false starts. These included: County of London Plan, 1943; London Transportation Study, 1968; London Rail Study, 1974; Central London Rail Study, 1989. In 1994, when the first Crossrail bill was voted out at parliamentary committee stage, a contemporaneous report declared the project was 'technically ahead of its time, but the politics and financing needs sorting out' (Financial Times, 14 January 1994).

The following 10 years were characterised by technical advances in materials, design and technical skills. Industry-wide experience of major rail projects such as the Channel Tunnel, the Jubilee line extension and Channel Tunnel Rail Link (High Speed 1) helped build technical and commercial confidence that the civil engineering challenges of the project could be met.

The passage of the 2005 bill was supported with an initial reference design containing strategic and outline proposals split geographically between four multi-disciplinary design consultants. These undertook option selection and progressed conceptual

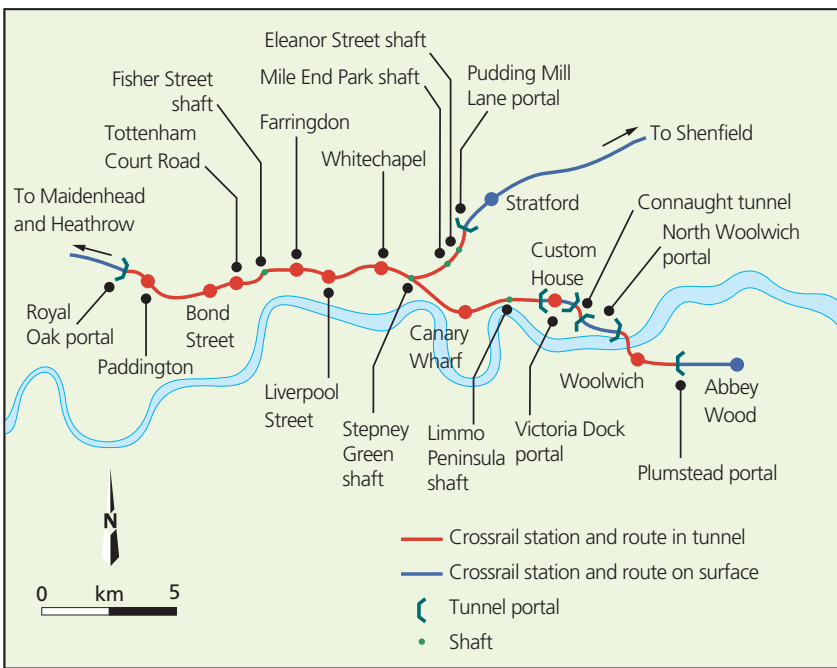

Figure 1. Plan of the central tunnelled section of the Elizabeth line

scheme designs for both stations and rail alignments. They collected and reviewed useful technical data on potential interfaces along the route such as utilities, existing geotechnical data and potential obstructions. A series of ground investigations began with input from the consultants to provide geotechnical and some environmental data (Black, 2017).

Final safeguarding of the route, which had been protected in the 1990s, followed in January 2008, with the alignment, limits of deviation and station provision fixed by the Crossrail Act 2008, which received royal assent in July 2008 (Crossrail Act 2008). In late 2008, detailed design packages were let to the framework design consultants by way of framework agreements. Twelve firms were awarded design work packages including tunnels, shafts, stations, portals and railway systems (see Tucker (2017), Table 1 for details).

The packages followed the Royal Institute of British Architects plan of work key stages (RIBA, 2007), with the framework design consultants instructed to develop the multi-disciplinary design consultant conceptual scheme designs through single option selection, RIBA stage D, to final proposals RIBA stage E. Crossrail elected to tender for construction based on this level of 
information. This approach was supported by several factors: the severe economic climate at the time (Gil and Lundrigan, 2013), a wariness of parties to commit to large packages of work, a change in the UK government contrasted with a desire to build momentum for the project.

Following issue of tender documentation, civil structures and tunnelling elements were progressed to a complete employer's design with product information, that is detailed design (RIBA stage F). The civil structures and tunnelling design elements were instructed under a variation to the construction contracts after the latter's award, for implementation. The employer's design for mechanical, electrical, public health and architectural elements remained at RIBA stage $\mathrm{E}$, requiring the contractor to undertake detailed design and coordination before construction (for Crossrail design timeline 2000-2016, please refer to Supplementary Figure 1. For RIBA plan of work $(2007,2013)$, please refer to Supplementary Figure 2).

\section{Detailed design procurement}

The procurement of framework design packages was based on a philosophy of clearly defined scope and design liability sitting with framework design consultants. The consultants were responsible for location-specific packages (e.g. stations, shafts) or technical disciplines (e.g. tunnels, ground movements) across several contracts.

The contracting approach can be attributed in part to the size of the Crossrail programme and perceived industry capacity, at the time, to execute large design packages. The side-effect was to create a significant number of design interfaces across disciplines, contracts and timescales, which required intensive collaboration between the design teams, and integration and coordination by Crossrail (see Supplementary Figure 3).

The employer's design was procured by Crossrail contracting directly with the framework design consultants and was awarded through 'work package orders' issued under the framework agreements. The frameworks and package orders were modified versions of the NEC3 Professional Services Contract (PSC) and were managed by project engineers or engineering managers within the chief engineer's group, part of the project's technical directorate.

PSC option $\mathrm{C}$ target contracts with activity schedules were predominantly chosen for the employer's design stage. PSC option E cost-reimbursable contracts were used on the framework design consultant's construction phase support activities, for efficiency and to support resource planning. Tasks were instructed using work orders, with a defined scope and deliverable dates to support the construction programmes.

\section{Design management plan}

At the start of design all framework design consultants and design-and-build designers had to complete a standardised design management plan, containing as a minimum

- applicable standards baseline and route to demonstration of compliance

- organisation chart and responsibilities

- skills matrix and levels of staff competencies
- scope definition and interface identification (including operational environment and requirements)

- projected output and defined deliverables

- stated processes and procedures to ensure acceptable quality assurance and records maintained

- process and procedures to ensure compliance with the engineering safety management system

- the design review process, single disciplinary review and interdisciplinary design review based on reviews at $+20 \%$, $+60 \%$ and $100 \%$ design completion.

- a description of how alignment with the programme requirements would be demonstrated

- how the supplier planned to monitor and report progress against cost and schedule.

Engineering progress and performance reporting tools were used by Crossrail to compare design completeness against cost and schedule. Areas that were typically reported for progress and measured on a periodic basis by the framework design consultants included

- safety and quality

- current status and work performed in period

- planned activities for next period

- issues and concerns

- risk

- key dates and milestones

- progress (earned value)

- man-hours and resource planning

- cash flow

- schedule and cost performance indicators

- deliverables monitored against time and budget.

It was the responsibility of the chief engineer's group to manage the framework design contracts and ensure collaboration and mutual trust thrived - which are essential behaviours for a project with multiple interfaces and emerging requirements.

The chief engineer's group acted as the technical authority for the project. This involved governing the safe, economic and efficient management of design outputs and ensuring conformance to standards and the project's programme functional requirements provided by the sponsors, the Department for Transport and Transport for London. The group also controlled the overall engineering design, including interfaces with the key industry partners, namely, London Underground, Rail for London and Network Rail.

The project organisational structure (see Tucker, 2017) created a healthy natural tension between project-implementation-focused teams and the technical-requirements-focused body. A key feature was that the engineering managers directly reported to the delivery directorate and functionally to the technical directorate (see Supplementary Figure 4).

\section{Geotechnical information and baseline reports}

The importance of comprehensive, high-standard, accurate geotechnical information on the project to control ground-related risk cannot be over-emphasised. Building on existing data collected by the framework design consultants, phased geotechnical 
investigations were scoped and managed by the programme development partner and framework design consultants utilising framework ground investigation contractors (Black, 2017).

The investigations were also monitored by an independent consultant to ensure that high standards of logging, sampling and laboratory testing and reporting were maintained across the project. The effort spent on these investigations led to the use of representative geotechnical parameters by the framework design consultants and the identification of key geotechnical risks. It is testament to this careful management that the project had no significant ground-related issues.

Crossrail provided geotechnical baseline reports as the contract baseline of geological conditions. The framework design consultants produced a series of geotechnical reports to inform the baseline reports (see Supplementary Figure 5).

\section{Safety in design}

The overall mandated strategy and approach throughout the project life cycle was set out in the engineering safety management system safety plan. All designers were required to provide assurance evidence that their design information complied with their obligations under the Construction (Design and Management) (CDM) Regulations (HMG, 2015) and The Workplace (Health, Safety and Welfare) Regulations 1992 (HMG, 1992).

The declaration was the final confirmation that the design was safe to build, operate and maintain. In most cases, Crossrail was both client and principal designer for projects it initiated, discharging CDM responsibilities through a range of post holders, with checks undertaken through a series of stop/go control points.

The designers were required to eliminate hazards where possible and reduce construction, operation and maintenance risks to be as low as reasonably practical (ALARP). Designers were required to carry out a designer's risk assessment to accompany their design from inception to issue of works information for construction.

Any strategic project risks identified by a framework design consultant were also fed into the programme and project risk registers. A number of strategic project level risks were also identified through this process, and these were elevated through the organisation for implementation of mitigation measures.

Safety in design was provided by the following.

- Assuring the level of individual competence: each framework design consultant undertook competency assessments for all their staff prior to engagement.

- Eliminating hazards and mitigation of risks in the design and its interfaces: this was achieved through the use of live risk registers and the use of safety, health and environment information on drawings ('SHE' boxes).

- Ensuring the design satisfied the project requirements.

- Evidence of safety in design was provided by the designers as part of the assurance gate process (see Section 10).

For the tunnels and underground construction works, the Joint Code of Practice for Risk Management of Tunnel Works in the UK (ABI/BTS, 2003) provided the benchmark for risk identification and allocation. In addition to conducting design reviews, the chief engineer's group was able to call on the services of an independent expert panel of specialists during the design and construction phases of the project. The expert panel comprised individuals who were appointed by the Institution of Civil Engineers to provide a balanced skill set for the critical duration of the underground works.

The panel provided a positive influence by challenging scheme designs as they evolved. Its involvement in design aspects naturally reduced as the project progressed and design teams grew in experience and confidence. It is likely that similar expert panels will feature on future major projects.

In addition, commitments made under paper D23 of the Crossrail Act ensured that the framework design consultants responsible for the permanent sprayed concrete lining tunnel design had a fully resourced presence on site to ensure that the design intent was maintained. This was important for the control and management of sprayed concrete lining tunnelling risks.

Having a continuous designer site presence helped with timely resolution of technical issues and communication of the basis of the design to site personnel. Disseminating knowledge and understanding of the design also focused value engineering initiatives and opportunities.

\section{Environmental management, sustainability and consents}

In common with all major UK construction projects, Crossrail was required to develop and implement an environmental management system. All designers were required to confirm that their design was compliant with the environmental minimum requirements of the Crossrail Act. This included demonstration of compliance with the parliamentary commitments (undertakings and assurances).

In accordance with the project's sustainability strategy, designers and contractors were required to identify environmental consents for their works and prepare consents applications. The project's planning, environment and traffic consents procedure ensured that the land-use planning, environmental and traffic consents needed were obtained on time to avoid programme delays and ensure compliance.

\section{Document control, computer-aided design and three-dimensional models}

Throughout the project, three different document management systems were used by Crossrail and its designers. The document numbering system was based on London Underground computeraided design standards and BS 1192 (BSI, 2016). The final document system used for the project was Enterprise Bridge by Bentley, the use of which was mandated in construction contracts.

All framework design consultant design and assurance documents were identified in a master deliverable list for each contract. Record and issue registers, listing the approved revisions for contractual drawings and specifications, were key to controlling design change and ensuring all parties were informed of the latest approved and assured information.

All permanent works computer models and drawings were prepared in accordance with the project's computer-aided design 
Crossrail project: engineering design management on the Elizabeth line, London

Barsam, Harris and Hooper standards using the electronic content management system, which contained BS 1192-approved workflows to manage and record all stages of the digital design production process. Bentley Microstation, Rebar and Projectwise were the software packages used.

The electronic content management system controlled authorisation of each stage of the workflow - preparers, checkers and approvers - based on the designer's competence management system. Once authorised for issue, all works information for construction was finally checked by Crossrail computer-aided design services for compliance with standards and evidence of gate certificates, and independent (category III) check certification. Electronic PDF files, generated as output deliverables from the content management system, were held in the document management system.

\subsection{Building information modelling}

Crossrail adopted building information modelling level 2 during the project to connect electronically the various three-dimensional models produced by the consultants with project documentation and asset information (Figures 2 and 3). This provided a consistent project-wide approach to the flow and production of information and helped manage design integration.

There was tension between appropriate use of three-dimensional modelling and the financial and delivery constraints to issue drawings for construction, an example being pressure to issue the two-dimensional drawings ahead of the three-dimensional model updates. Suitable hardware to undertake the work was essential,

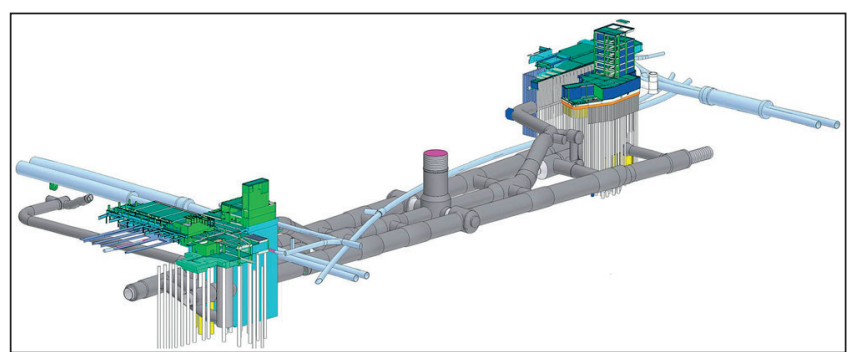

Figure 2. Three-dimensional computer-aided design model of the Elizabeth line Liverpool Street station with connections to London Underground stations at Moorgate and Liverpool Street

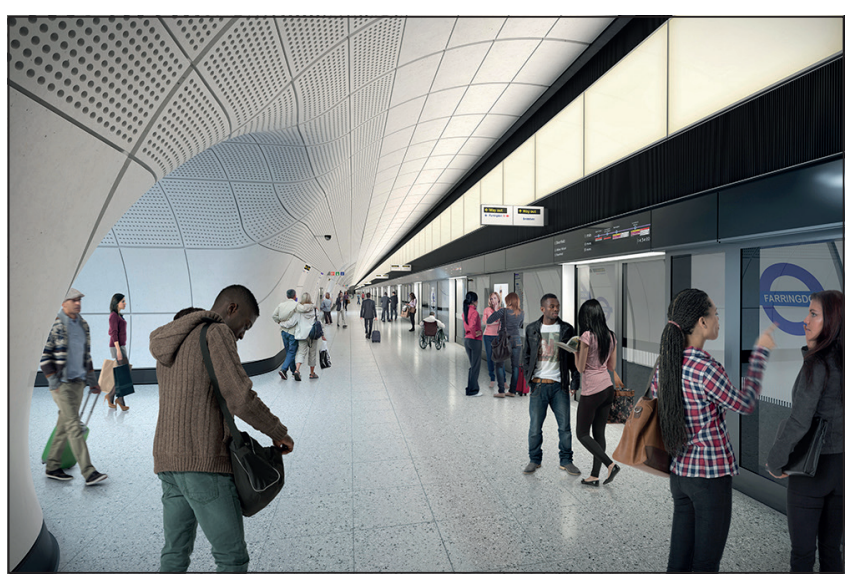

Figure 3. Rendered image of Farringdon station platform such as computers with sufficient processing power and network connections.

\subsection{Temporary works design}

Temporary works design, including sequencing and methodology, was the responsibility of the contractors. However, the employer's permanent works designers had an obligation to provide feasible solutions and, under CDM obligations, consider and identify specific measures necessary for the safe implementation of their designs. This often led to a prescribed construction sequence that supported the basis of the design.

Under the contractor's works information, responsibility for construction sequence and methodology belonged to the contractor. Therefore, in a number of instances, redesign by the employer's designer was accepted as necessary for reasons of sequencing and methodology. These changes were mainly proposed through the contract's value engineering mechanism and supported with both a technical and business case for review by the employer. As a result there were relatively few temporary works issues.

Temporary works were designed and assured against the contractor's own in-house procedures. Crossrail produced a temporary works procedure to ensure a consistent approach across the various contracts. This included mandating the preparation of a design brief, the appointment of a temporary works coordinator and establishing principles for the expected level of design checking.

\subsection{Division of responsibility}

For the sprayed concrete lining tunnels, relationships between the permanent lining works and temporary sequencing and methodology were inherently linked within the employer's design. To ensure the employer's design remained valid and integrated with the contractor's sequencing, methodology and responsibilities, a design process and detailed division of responsibility was established (Figure 4). This aligned the employer's design with the contractor's planned tunnel excavation sequencing, construction plant and contractor-designed 'tool box' measures to deal with temporary conditions.

Particular contract terms were interpreted differently on the various projects, with a different allocation of risk and commercial implications for both employer and contractor. This resulted in each of the five sprayed concrete lining contracts having a distinct division of responsibility profile, which took considerable time to finalise.

\section{Design control}

All plans, processes and procedures were structured in their hierarchy and communicated through the project's management system. The project's standards baseline was the list of approved design standards for design, construction and commissioning. The standards baseline was a combination of British and European standards and codes of practice, including the project's civil engineering design standards, and those of Network Rail and London Underground. It was fixed when RIBA Stage D was instructed.

The civil engineering design standards provided a robust set of requirements with moderately conservative parameters, which helped drive consistency and configuration control across the design and checking teams. They did not provide an incentive to 
Civil Engineering

Volume 170 Issue CE5
Crossrail project: engineering design management

on the Elizabeth line, London

Barsam, Harris and Hooper

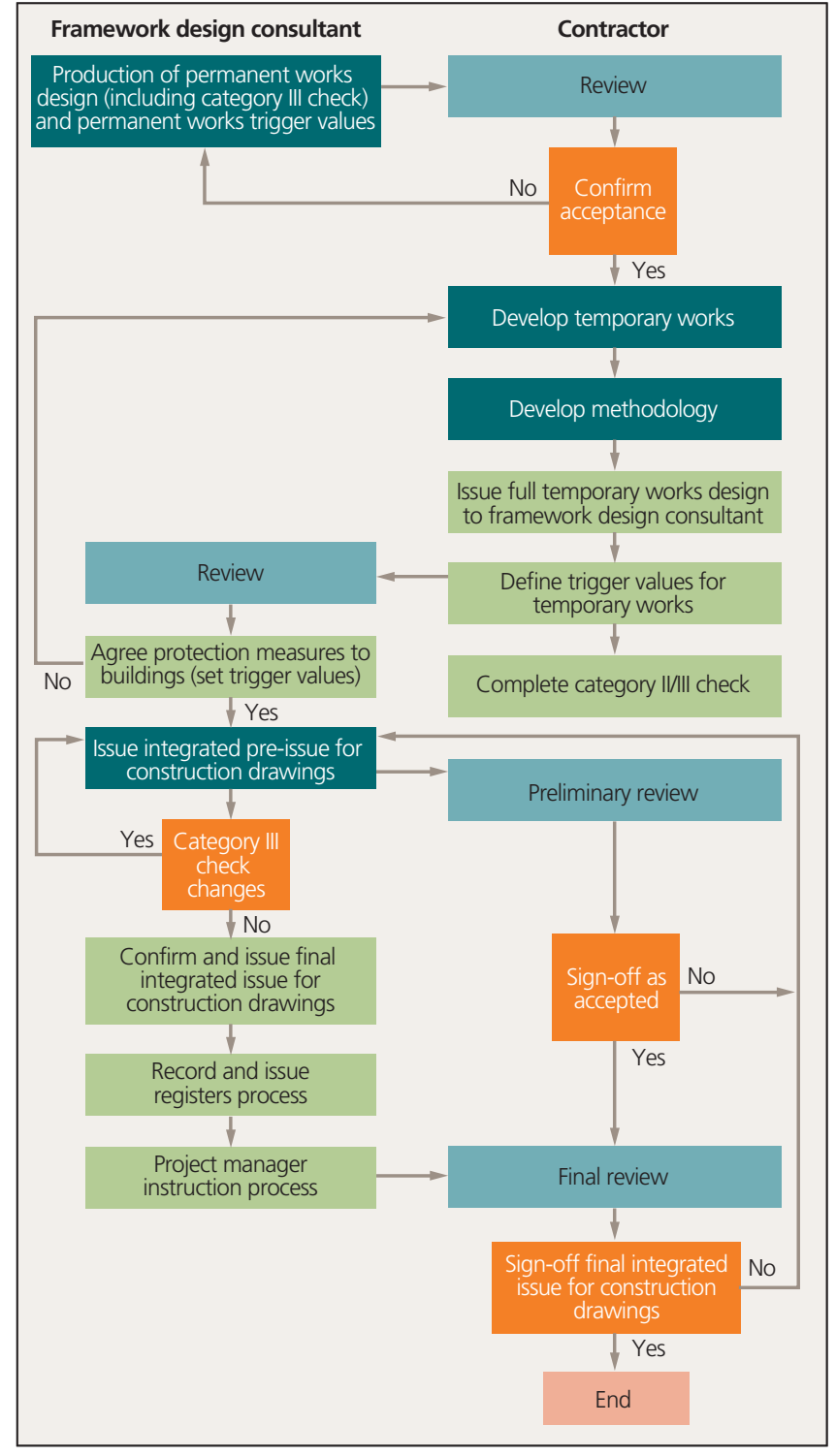

Figure 4. Division of responsibility for a single sprayed concrete lining tunnel contract

adopt more economic design approaches, as departures from the standards required concessions. Approval of concessions often required detailed justifications with back up for both internal and future maintainer approval.

Although there was standardisation of design details across the project, many local differences were adopted for various reasons. Any departures against requirements in the standards baseline required concessions to be sought through the chief engineer's group or the relevant infrastructure maintainer - London Underground or Rail for London.

\subsection{Assumptions management}

Design assumptions which were needed to progress were managed by the designer as part of the project's requirements management plan using an assumptions register stored in a dynamic object-orientated requirements system database.
Most assumptions were temporary and were closed out by the time of issue of construction drawings. Some assumptions were agreed to be turned into requirements, such as when it was not possible to coordinate interfacing conditions directly with the follow-on supplier.

\subsection{Management of design documentation}

Each framework design consultant was required to maintain a single register and issue record containing the latest list of all drawings and design documents generated on that specific contract. This process was also adopted for the contractor's design stage, with each construction contract required to maintain a register and issue record for its design outputs.

Documentation and deliverables as specified in contracts were also required to be entered onto the contract master deliverables list. This also contained planned issue dates for acceptance by the employer.

\subsection{Interface design coordination}

Owing to the scale of the project and numerous interfaces between framework design consultants, interface control documents were used to document and formalise agreements between organisations that interfaced. These recorded how the design scope and responsibilities were allocated, including agreed space-proofing, reference drawings, design loadings and threedimensional digital model information. One of the challenges for the interface control was that different consultants were at various stages of design because contracts had been let at different times.

Documenting responsibilities to a sufficient level of detail was difficult, particularly during times of continuous change: where there was an interface, there was often a problem. The success of the documents relied on co-operation and collaboration between framework design consultants, which was testament to Crossrail's values as noted in section 1 . As elements of the project moved from employer's design to the contractor's design responsibility, new interface control documents were required between interfacing construction contracts with design responsibilities.

The co-location of several framework design consultants' entire teams on a single floor in a modern, well-appointed, open-plan Transport for London office in Greenwich greatly encouraged co-operation between individuals and firms, to everyone's benefit.

\subsection{Optimum contractor involvement period}

To encourage contractor input into the design following the construction contract award, a period of optimum contractor involvement was allowed. This aimed to encourage potential savings in cost and programme which, once assessed by the client could, if acceptable, be incorporated into the employer's design.

It is arguable whether the timing at the start of the construction contract and the stipulated 90 days allocated for optimum contractor involvement was sufficient, given that often key design and construction expertise was not fully mobilised. Ideas generated were typically embryonic and there was a reluctance to embark on significant redesign at the start of construction.

Consequently, some changes advantageous to the project's delivery were identified late in the programme and some opportunities were missed. An example was a proposal to standardise the diameters of cross-passages in stations. This opportunity was missed due to initial concerns over space-proofing 
and ground movements. Optimal contractor involvement did, however, bring teams together to challenge the design and set the scene for encouraging value engineering proposals.

\subsection{Value engineering}

The stated aim of Crossrail engineering design was to "produce safe, economic and compliant designs that produced the lowest total installed cost'. To maximise opportunities to reduce the total installed cost, value engineering was conducted throughout the life cycle of the project.

It was recognised that early value engineering initiatives with robust business cases usually yielded the greatest savings in cost and programme.

\subsection{Minor and major design change}

In addition to optimal contractor involvement and value engineering, there were several sources of design change that occurred during detailed design and after issue of construction drawings. These had to be carefully managed and accommodated within the design programmes to ensure existing commitments could be met.

Sources of design change included

- optimal contractor involvement

- redesign to address construction non-conformance reports

- contractor's preferred method of construction

- change to contractor's preferred method of construction

- change to construction programme (e.g. acceleration; tunnelboring machine drive interfaces, particularly at stations)

- construction constraints (e.g. site access)

- discovery on site of conditions different from the design assumptions

- value engineering proposals (offering programme and cost savings)

- changing requirements of interfacing design or construction contracts

- changes to sponsor's requirements (e.g. additional lifts and stairways)

- minor on-site changes to construction details ("field change documents')

- requests for information field changes and non-conformances.

Examples of design change ranged from minor changes to reinforcement to suit buildability to new temporary tunnels to allow station works to progress during tunnel-boring machine arrivals, unlocking programme benefits.

Responses to minor design changes and clarifications were formalised by way of the electronic project technical request system with requests for information and field change documents (Figure 5). However, major design changes (typically those that could not be closed within 2 days) would often require significant coordination, redesign and analysis, independent category III checking and gate impact reviews (see Section 10) and capturing revisions in final design submissions (see Section 8).

The design and assurance programme constraints put significant pressure on the design teams and their management, but also helped to filter out those proposed changes for which the benefits were marginal.

Designers were required to monitor and control change according to the following principles both pre- and post-issued-forconstruction documentation status
- produce an audit trail to track changes (e.g. design and check certificates, change logs, revised interface control documents)

- ensure that change was supported by an authorised instruction

- maintain configuration control so that impacts on interfaces were understood and accounted for

- ensure the cost of the change was accurately estimated and incorporated in the cost forecast.

The managers of engineering and engineering managers were responsible for managing the assured state of design changes identified after construction issue. Similarly, on any design change identified through the project technical request procedure, the managers of engineering and engineering managers were responsible for evaluating the risks and impact against Gates criteria (see Section 10).

To provide early indications of potential variance to the baseline cost and programme, strong governance and process was applied to controlling change, managing budgets and forecasting trends. Reviews were undertaken by design, cost, contract and construction teams in the project's delivery organisation to enable handover and acceptance for implementation.

The project's change paper control process required the promoter of a change to attend a series of four interrogative panels and reviews over a minimum of 4 weeks. This allowed time for the promoter to gather additional supporting information on the wider technical and financial implications of the change. The process had a 'filtering effect' ensuring that only essential changes were assessed and endorsed by the commercial and contracts subcommittee.

\subsection{Design and checking certification}

Design certificates contained the assurance evidence trail from the initial work package to the final assured design deliverables. Designs were category I, II or III checked, depending on their risk profile, in accordance with the project's civil engineering design standards. The independent category III checking process was managed by the relevant framework design consultant and overseen by the chief engineer's group.

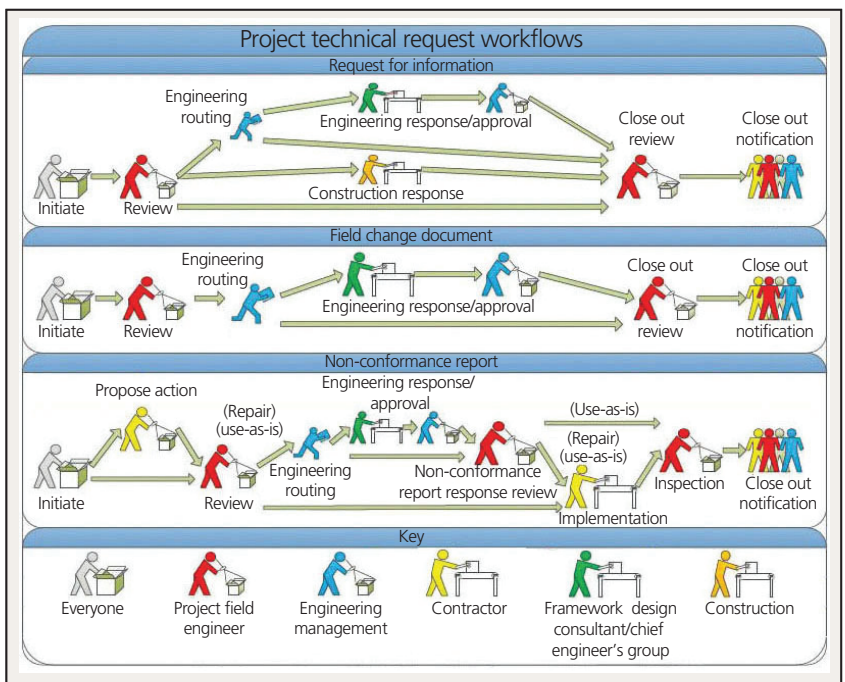

Figure 5. Project technical request workflow process 
Final design statements included a design completion certificate certifying the design was in accordance with all project requirements, providing assurance to Crossrail and the future maintainer. Construction verification completion certificates were prepared by the designer for sprayed concrete lining tunnel works, confirming that construction had complied with design requirements or, if not, how this had been mitigated.

\section{Design review process}

The review process comprised design reviews, gate reviews and readiness reviews.

\subsection{Design reviews}

The design review procedure covered the preparation and attendance at single disciplinary reviews and inter-disciplinary reviews. The latter were attended by the Chief Engineer's group, the CDM coordinator, interfacing framework design consultants and third parties including the infrastructure maintainers. Digital models applicable to design submissions were required to be part of the formal reviews and were shared with interfacing designers using Bentley Projectwise.

\subsection{Gate reviews}

All designs were subject to a three-stage Gate review (Figure 6)

- Gate 1: final scheme design - design $20 \%$ complete - RIBA stages $\mathrm{C}$ and $\mathrm{D}$

- Gate 2: intermediate design (single option) - design $60 \%$ complete - RIBA stage E

- Gate 3: issue for construction - RIBA stage F (detailed design, tender documents, production information $-100 \%$ design completion).

Each gate review allowed progressive assurance to be demonstrated to both internal and external stakeholders, while also driving design delivery milestones. The gates process was not a review of the design but a review of evidence of satisfactory progress and completion of the design and dedicated assurance

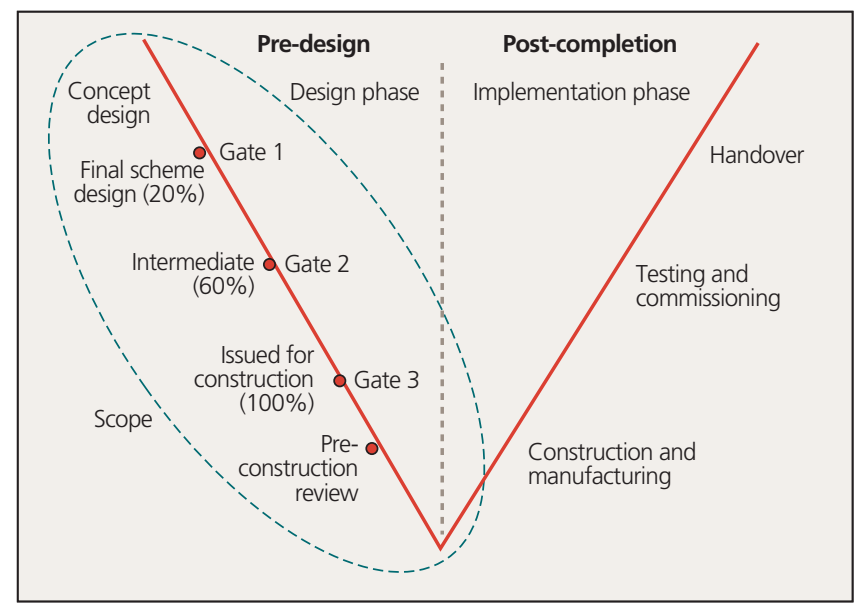

Figure 6. Simplified ' $V$ ' model showing design gates and Royal Institute of British Architects stages activities. The design team were required to present evidence to the gates' chair and panel against ten criteria, namely meeting project requirements, compliance with the Crossrail Act 2008, conformance to standards, design for safety, affordability, management of risk, coordination, constructability, quality and project schedule.

The Gate 3 pass certificate was required to allow issue of the construction drawings to site.

The gates process was mutually beneficial for the designers and employer. It encouraged collaborative behaviours between the interfacing framework design consultants and provided the employer with a level of confidence in the thoroughness of the designers and their design deliverables. It was not only a valuable way of demonstrating assurance, but also an effective means of risk management.

Where the 'gated design' was changed due to a redesign that would impact the future maintainer (e.g. space-proofing, change to maintenance regime), a mini-gate (i.e. a scaled-down gate review) and a gate impact report were required. These design changes might have been initiated by value engineering proposals, or changes in construction method or sequencing.

\section{Third-party interfaces}

Owing to the numerous interfaces involved in constructing new stations and tunnels through London, third-party interfaces such as with statutory utilities, London Underground, Rail for London, Network Rail and existing landowners required careful management. During the detailed design process, framework design consultants' contact with third parties was managed by Crossrail. This ensured control of information and design coordination, and also ensured that stakeholders were not overwhelmed with requests.

The integration of requirements for commercial over-site developments into the station design schemes proved particularly challenging for designers. Future projects would benefit from understanding the importance of an early integration of over-site development design (which by its nature often follows months, and sometimes years, behind). Early development of over-site development interface requirements and assumptions is essential.

\section{Discussion, reflections and recommendations}

The processes described in this paper were needed to deliver an integrated employer's design for London's newest railway. The size and complexity of the project stretched resources at all levels of the organisations involved in the project.

The numerous design and construction interfaces created by the procurement strategy required careful and proactive management. Clear definitions of responsibilities, and formal and informal communication of these responsibilities to all relevant parties were required.

Control of the processes became more rigorous as the project developed. This helped to ensure that technical requirements were met, configured correctly and the scope could be delivered to the required quality, cost, risk and schedule envelope.

There are many lessons to be learnt from the design development of the Elizabeth line. The authors wish to highlight three for further discussion and debate. 


\subsection{Design interfaces}

The early decisions taken on design procurement strategy and technical requirements reverberated through the project's life cycle. Minimising interfaces and reducing complexity across design and construction contract packages should be given greater attention and planned for on future major projects.

Design packages for the Elizabeth line's precursors - the Victoria line and Jubilee line extension (East and Mitchell, 1999) - were split geographically to reduce interfaces and perhaps this approach will be revisited.

\subsection{Geotechnical information}

The high standard of geotechnical investigation and reporting helped to control the major risk for sub-surface construction. There was sufficient quality and quantity of information to ensure ground conditions were properly characterised and this was a major element in the project's success.

\subsection{Design development}

The management of risk and construction delivery on the project benefitted from the programme's long period of design development. As a result, no fundamentally significant changes in design concept were needed during the implementation phase of the project.

The pros and cons of an employer's design compared with a contractor-led design and build project has been debated since the 1980s. There is a perception that the latter can 'drive delivery harder', reducing costs and uncertainty. These claims need to be critically evaluated along with who is best placed to manage risk. This applies particularly to rail projects given their wider integration, interface challenges and public profile.

On the Elizabeth line, with its complex interfaces and procurement strategy, a fully engineered employer's civil and structural design, owned by an 'intelligent client', enabled risk to be efficiently managed with integration and interfacing parties from an early stage. Furthermore, continuity of the employer's technical team during design development, and into the construction phase, ensured that the design intent was communicated and site issues were addressed and responded to in a proactive manner. Where a change was deemed necessary, it was managed in full knowledge of the design requirements that needed to be maintained.

\section{Conclusions}

This paper describes the essential 'continuous thread' of design management (Muir Wood, 2000) for the central tunnelled section of the Crossrail project to build the Elizabeth line across London. It explains how the processes, procedures and areas of responsibilities of the designers and employer needed to be robust and resilient to cope with the scale and complexity of the interfaces.

In particular, it shows how the selected size and procurement of design packages required careful management of numerous interfaces, during design change, and the challenges this posed. Through the processes described in this paper, the employer's design provided the project sponsors and client organisation with the confidence that the wider integration and interface challenges, as demanded by a modern twenty-first century railway, have been successfully met.

\section{Acknowledgments}

The authors would like to acknowledge and record their appreciation for the often-unrecognised work and efforts of the many hundreds of engineers, technicians and surveyors involved in the planning, site investigations and design of the Crossrail project, in its many forms and guises. The opening of the Elizabeth line will be the culmination of a vision born during the darkest days of the Second World War, developed and sustained over the following decades, and a tribute to the achievements of many individuals and teams.

\section{References}

Abercrombie P and Forshaw JH (1943) County of London Plan. London County Council, MacMillan and Co Ltd, London, UK.

ABI/BTS (Association of British Insurers/British Tunnelling Society) (2003) The Joint Code of Practice for Risk Management of Tunnel Works in the UK. Association of British Insurers/British Tunnelling Society, London, UK.

Black M (2017) Crossrail project: managing geotechnical risk on London's Elizabeth line. Proceedings of the Institution of Civil Engineers - Civil Engineering 170(5): 23-30, http://dx.doi.org/10.1680/jcien.16.00024.

Bovis, Gibb A, MVA Consultancy et al. (1993) Crossrail Cost Effectiveness. Report commissioned by the Department for Transport, London, UK.

British Transport Commission (1949) London Railways Plan. British Transport Commission, London, UK.

BSI (2016) BS 1192:2007+A2:2016 Collaborative production of architectural engineering and construction information. Code of practice. BSI, London, UK.

Crossrail (2016) Crossrail - From its Early Beginnings. See http://www.crossrail.co.uk/route/crossrail-from-its-early-beginnings (accessed 13/07/2016)

Crossrail Act 2008. Chapter 18. Her Majesty's Stationery Office, London, UK

DfT (Department for Transport) (1989) Central London Rail Study. Department for Transport, London, UK.

East RW and Mitchell RF (1999) Project management of the Jubilee line extension. Proceedings of the Institution of Civil Engineers - Civil Engineering 132(6): 11-18, http://dx.doi.org/10.1680/ icien.1999.132.6.11

Fergusson JC (2001) Crossrail: Scope, background and feasibility. Proceedings of the Institution of Civil Engineers - Transport 147(2): 61-69, http://dx. doi.org/10.1680/tran.2001.147.2.61.

Gil N and Lundrigan C (2013) Crossrail; The Perfect Storm (A). University of Manchester, Manchester, UK, Megaproject Leadership and Governance Case Study Series.

Greater London Council and Department for Environment (1974) London Rail Study. Greater London Council and Department for Environment, London, UK.

HMG (Her Majesty's Government) (1992) The Workplace (Health, Safety and Welfare) Regulations 1992. The Stationery Office, London, UK, Statutory Instrument 1992 No. 3004.

HMG (2015) Construction (Design and Management) Regulations 2015. The Stationery Office, London, UK, Statutory Instrument 2015 No. 51.

Muir Wood A (2000) Tunnelling: Management by Design. E \& FN Spon, London, UK.

RIBA (Royal Institute of British Architects) (2007) Outline Plan of Work 2007. RIBA, London, UK.

Tucker W (2017) Crossrail project: the execution strategy for delivering London's Elizabeth line. Proceedings of the Institution of Civil Engineers Civil Engineering 170(5): 3-14, http://dx.doi.org/10.1680/jcien.16.00021. 